\title{
Prevalence and site of bacteriuria in diabetes mellitus
}

\author{
BoON Seng OOI \\ M.B., M.R.A.C.P.
}

\author{
BeAtrice T. M. Chen \\ M.B., F.R.A.C.P.
}

\author{
Moses Yu \\ M.B., DIP.BACT. \\ Department of Medicine, University of Singapore, and Department of Bacteriology, \\ Outram Road General Hospital, Singapore 3
}

\begin{abstract}
Summary
Twenty-four of 152 female diabetic patients $(15 \cdot 8 \%)$ were found to have significant bacteriuria as compared to a prevalence rate of only $4.6 \%$ of 152 matched non-diabetic controls. The difference in prevalence rates is statistically significant. However, if the prevalence rates are analysed according to age, bacteriuria was significantly more common only in diabetic females above the age of 50 . Localization of site of infection was performed in all diabetic female subjects with bacteriuria. The kidney was affected in $62.5 \%$ of patients. The pathogenetic considerations relating to these results are discussed. There was no difference in prevalence rate of bacteriuria between male diabetics and their controls.
\end{abstract}

IT has been traditionally held that patients with diabetes mellitus have an increased susceptibility to urinary tract infections. This view stems from autopsy findings and largely uncontrolled clinical observations. Such studies suffer from several limitations, and the data have been critically reviewed by Vejlsgaard (1965). More recent investigations using quantitative bacteriological methods and matched controls have, however, been inconclusive. An increased prevalence of urinary tract infections has been found by Vejlsgaard (1965), while Huvos and Rocha (1959), O'Sullivan et al. (1961) and Pometta et al. (1967) could find no evidence of an increased susceptibility to such infections. The question must therefore still be regarded as being open. The present study was undertaken to re-examine this problem. In addition, we have localized the site of infection in affected patients to assess if the diabetic kidney is more prone to harbour infections, and to assess the extent of functional and morphological impairment of such a kidney by physiological and radiographic methods.

\section{Materials and methods}

The patients studied were 154 male and 152 female diabetic patients referred from outpatient clinics. Patients with hypertension as defined by a diastolic level of $100 \mathrm{mmHg}$ were excluded from the study. Age, parity of female subjects, and duration of diabetes from the time of diagnosis were recorded. Controls were drawn from a non-renal outpatient population and were matched in terms of sex, age in decades, and parity. Patients found to have significant bacteriuria were questioned closely about a history of urethral instrumentation and urologic operations. Mid-stream specimens of urine (after peri-urethral cleansing with antiseptic soap solution in female patients) were obtained from patients on 3 consecutive occasions at weekly intervals. Quantitative bacterial cultures were performed by the streakplate technique (McGeachie and Kennedy, 1963). Significant bacteriuria was diagnosed when 2 consecutive samples demonstrated the presence of more than 100,000 organisms $/ \mathrm{ml}$. In addition, urinalysis was performed on sediment obtained on centrifuging $10 \mathrm{ml}$ of urine. Pyuria was diagnosed when there were more than 20 white blood cells/high power field. Localization of the site of infection was done on female patients with bacteriuria by the technique described by Fairley et al. (1967). The criteria for the diagnosis of upper or of lower urinary tract infection are the same as those of Fairley et al. (1967). The test was repeated in five subjects to determine its reproducibility, and results obtained were similar on both occasions in all subjects. One subject whose results were inconclusive also had a repeat test. All bacteriuric patients had their renal concentrating capacity assessed by measurement of urinary osmolality after administration of pitressin tannate in oil (Ooi and Kincaid-Smith, 1969). Intravenous pyelograms were also performed on all bacteriuric 
TABLE 1. Distribution of diabetic and control population by age and sex with corresponding numbers of subjects with bacteriuria

\begin{tabular}{lccccccc}
\hline & $10-19$ & $20-29$ & $30-39$ & $40-49$ & $50-59$ & 60 & Total \\
\hline Diabetic females & $1(0)$ & $7(1)$ & $11(1)$ & $32(3)$ & $48(5)$ & $53(14)$ & $152(24)$ \\
Healthy females & $0(0)$ & $9(0)$ & $11(0)$ & $30(1)$ & $49(2)$ & $53(4)$ & $152(7)$ \\
Diabetic males & $0(0)$ & $3(0)$ & $15(0)$ & $52(0)$ & $58(1)$ & $26(1)$ & $154(2)$ \\
Healthy males & $0(0)$ & $5(0)$ & $15(0)$ & $49(0)$ & $58(0)$ & $32(1)$ & $159(1)$ \\
\hline
\end{tabular}

Figures in parenthesis refer to numbers of subjects with bacteriuria.

subjects. Statistical analysis was done by the $\chi^{2}$ test, applying Yates' correction.

\section{Results}

The age and sex distribution of diabetic and nondiabetic populations are shown in Table 1. Twenty-four of 152 female diabetic patients $(15.8 \%)$ were found to have significant bacteriuria; five of fifty-one $(9.8 \%)$ were below the age of fifty, and nineteen of 101 $(18.8 \%)$ were above that age. By comparison, only seven non-diabetic females $(4.6 \%)$ had bacteriuria; one of fifty $(2 \%)$ was below the age of 50 , and six of $102(5.8 \%)$ above that age. The differences in overall prevalence between diabetic females and control subjects are statistically significant $\left(\chi^{2}=\right.$ 9.1 $P<0.01)$. However, if the differences are analysed in relation to age, we find that no significant difference was observed between diabetics and controls below the age of $50\left(\chi^{2}=1.53 \quad P>0.05\right)$. The differences were, however, significant for subjects above the age of $50\left(\chi^{2}=6.7 P<0.01\right)$. Among diabetic females, there was no relationship between frequency of bacteriuria and number of past pregnancies, $14 \%$ of 100 subjects with less than five pregnancies having significant bacteriuria, against $19 \%$ of fifty-two subjects with five pregnancies or more. There was also no significant correlation between the prevalence rate of bacteriuria and the duration of diabetes, although the prevalence rate was higher in diabetics of more than 5 years $(20.5 \%$ of sixty-eight patients) than in diabetics of less than 5 years duration $(11.9 \%$ of eighty-four patients).

All twenty-four bacteriuric patients had persistent pyuria; an additional eight patients with sterile urine also excreted pathological numbers of white blood cells.

Of 24 pyelograms four were abnormal, a calculus being present in three patients, and a calyceal cyst in one. None of the pyelograms demonstrated any change characteristic of chronic pyelonephritis. If the three patients above the age of 50 having abnormal pyelograms are omitted from the study, the differences in prevalence rate of bacteriuria between diabetics and controls are still significant $\left(\chi^{2}=\right.$ $4.55 P<0.05)$.

The kidney was found to be the site of infection in fifteen of twenty-four women patients $(62 \cdot 5 \%)$. The concentrating capacity was impaired in all these fifteen patients as assessed by the inability to concentrate urine above $700 \mathrm{mOsms} / \mathrm{l}$. In contrast, all patients with bladder infections retained normal concentrating function.

Only two of the female patients admitted to having been catheterized.

Of the men only two had significant bacteriuria, and in the control population only one. In addition, another two male diabetics had persistent pyuria. Intravenous pyelograms were normal in both male diabetics as was concentrating ability of the kidneys.

\section{Discussion}

The present study lends support to the thesis that there is an increased susceptibility to urinary tract infections in female diabetics above the age of 50. There is also an increased prevalence of bacteriuria in the younger diabetics when compared to a contro population although the differences are not statistically significant. Our study confirms the results reported by Vejlsgaard (1965) who, however, did not report any differences between succeeding age groups; it was, however, apparent from his data that the highest prevalence rate of bacteriuria was recorded in the age group 60-69. In fact, when diabetic girls between the ages of 6-15 were screened for bacteriuria, no increase in prevalence rate was detected by Pometta et al. (1967). It would appear that diabetes mellitus in association with age predisposes the urinary tract to infection. Our study demonstrates that this is not a function of the duration of the disease, number of previous pregnancies, or of past urethral instrumentation, confirming the observations of Vejlsgaard (1965). Contrary observations on the susceptibility of diabetics to urinary tract infection have been reported by Huvos and Rocha (1959), O'Sullivan et al. (1961) and Pometta et al. (1967). In the first study, the most striking finding is the very high prevalence rate of bacteriuria in the control population $-22 \%$ of women. The authors suggested that this might be accounted for by the fact that the control population suffered from various debilitating diseases. They conceded that their data did not rule out diabetes as a factor predisposing to infections; such predisposition if it existed was being obscured by other factors such as age, and debility. 
Similar arguments may be advanced against the study described by O'Sullivan et al. (1961). In both studies, a significantly higher prevalence of bacteriuria was detected in older patients than younger. The results described by Pometta et al. (1967) cannot be compared to those obtained in the present study, since their investigations were confined to young girls.

The site of urinary tract infection in diabetics has not to our knowledge been previously reported. Our finding that $62.5 \%$ of infections of the urinary tract of diabetic women are renal in origin suggests that there is only a slightly increased predisposition of the diabetic kidney to become infected. In a study of acute urinary tract infections in general practice by Fairley et al. (1971), half of the patients had their infection confined to the bladder, while in the other half it was localized in the kidney. Our investigation suggests that diabetes, probably in association with ageing, accentuates factors which allow the establishment of infection in non-diabetic persons, rather than specially predisposing the kidney to infection.

It is also interesting that all diabetic women with renal infections had impaired concentrating ability of the kidney. This contrasts to a study of urinary tract infections in general when only about a third of patients with upper urinary tract infections had reduced concentrating ability (Ooi and KincaidSmith, 1969). This suggests that diabetic patients may have bilateral infections, or that some other factor, e.g. diabetic vascular changes of the vasa recta, contributes towards this type of functional impairment.

As in previous studies (Huvos and Rocha, 1959; O'Sullivan et al., 1961; Vejlsgaard, 1965), our results do not show an increase in prevalence of bacteriuria amongst diabetic men.

\section{References}

FAIRLEY, K.F., Bond, A.G., Brown, R.B. \& HABERSBERger, P. (1967) Simple test to determine the site of urinary tract infection. Lancet, ii, 427.

Fairley, K.F., Grounds, A.D., Carson, N.E., Laird, E.C., Gutch, R.C., McCallum, P.H.G., Leighton, P., SleeMAN, R.L. \& O'Keefe, C.M. (1971) Site of infection in acute urinary tract infection in general practice. Lancet, ii, 615.

Huvos, A. \& Rocha, H. (1959) Frequency of bacteriuria in patients with diabetes mellitus. New England Journal of Medicine, 261, 1213.

McGeachie, J. \& Kennedy, A.C. (1963) Quantitative methods for bacteriuria and pyuria. Journal of Clinical Pathology, 16, 32.

OoI, B.S. \& Kincaid-Smith, P. (1969) Urine concentration after pitressin administration in upper and lower urinary tract infection. Medical Journal of Australia, 1, 982.

O'Sullivan, D.J., Fitzgerald, M.G., Meywell, M.J. \& MALINS, J.M. (1961) Urinary tract infections, a comparative study in diabetic and in general population. British Medical Journal, 1, 786.

Pometta, D., Rees, S.B., Younger, D. \& Kass, E.H. (1967) Asymptomatic bacteriuria in diabetes mellitus. New England Journal of Medicine, 276, 1118.

VEJLSGAARD, R. (1965) Bacteriuria in patients with diabetes mellitus. In: Progress in Pyelonephritis (Ed. by E. H. Kass), p. 478. Philadelphia, Davis. 